\title{
Effects of Flowable Composite Resin and curing method on Microleakage
}

Neam N Al-Yousifany BDS, MDSc ( Lect)

\author{
Department of Conservative Dentistry \\ College of Dentistry, University of Mosul
}

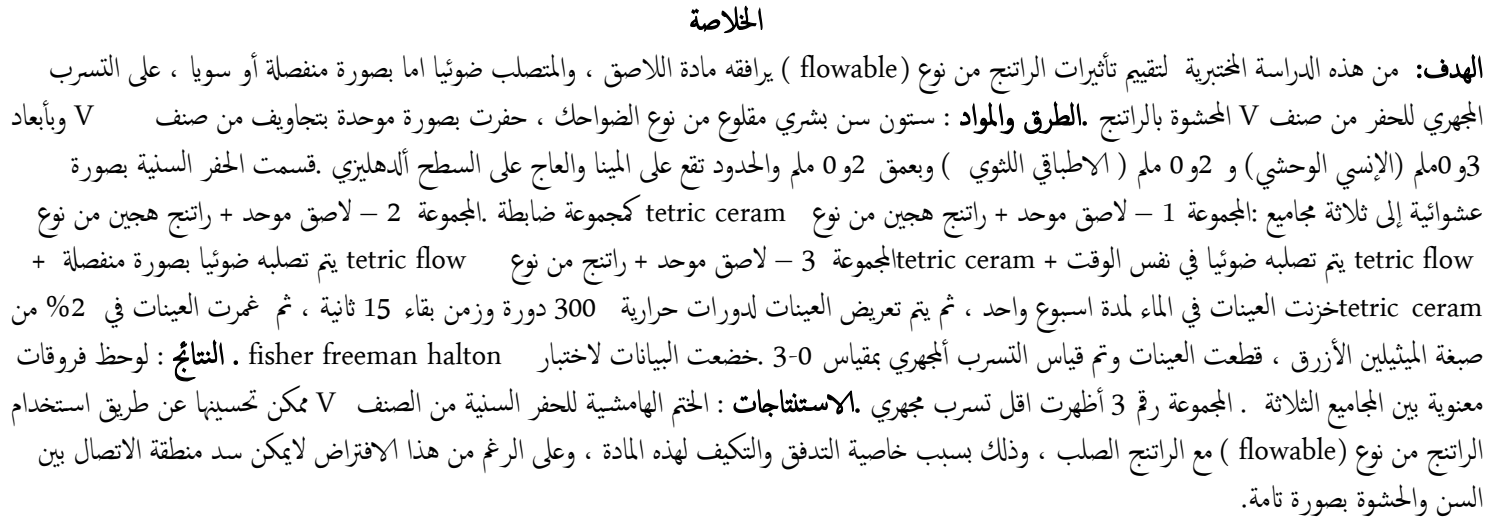

\section{ABSTRACT}

Aims: The purpose of this invitro study was to evaluate the effects of a flowable composite associated with an adhesive, either light cured separately or co-cured on the microleakage of class $\mathrm{V}$ composite restorations. Material and methods: Sixty extracted human premolars were prepared with standardized box shaped class $V$ cavities of $3.0 \mathrm{~mm}$ (Mesial distal), 2. $\mathrm{mm}$ (occlusal gingival) and $2.0 \mathrm{~mm}$ depth with margins located on enamel and dentin on the buccal surfaces. The cavities were randomly assigned in the three groups $(\mathrm{n}=20)$ : Group 1- single bond + tetric ceram (hybrid composite) as control group. Group 2- single bond + tetric flow (flowable composite) light cured simultaneously + tetric ceram. Group 3- single bond + tetric flow light cured separately + tetric ceram. After storage period of one week in water, All specimens were thermo-cycled for 300 times with 15 seconds dwell time, and immersed in $2 \%$ methylene blue, sectioned and evaluated for microleakage using 0-3 scale. Data were subjected to Fisher Freeman Halton test at $p<0.05$. Results: Statistical significant differences between the three tested groups was observed. Group 3 (Flowable and adhesive cured separately) revealed the less microleakage. Conclusions: The marginal seal of $\mathrm{Cl} \mathrm{V}$ cavities could improved by the use of flowable resin with rigid composite resin, but even with supposedly better flow and adaptation characteristic of this material it could not completely sealed the tooth/ restoration interface especially at the cervical margins.

Key words: Flowable composite, microleakage, composite resin, co-cured, class V.

Al-Yousifany NN. Effects of flowable composite resin and curing method on microleakage. $\mathrm{Al}$ Rafidain Dent J. 2010; 10(1):1-7 .

Received: $26 / 8 / 2007$

Sent to Referees: $26 / 8 / 2007$

Accepted for Publication: 27/9/2007

\section{INTRODUCTION}

Resin composite are routinely used as restorative materials in anterior and posterior teeth due to their excellent elastic qualities ${ }^{(1)}$.

However, polymerization shrinkage of resin matrix is still considered highly relevant in unsuccessful resin composite direct restoration ${ }^{(2)}$.
The forces generated by polymerization shrinkage may induce stresses that could break the bonding at the cavity walls. which is one of the main causes of marginal failure ad subsequent, microleakage $^{(3)}$.

Marginal microleakage is defined as the penetration of acid, enzymes, ions, bacteria and bacterial products between 
cavity wall and the restorative material, and its responsible for marginal discoloration, post operative sensitivity, secondary, secondary caries and pulp damage ${ }^{(4)}$.

In modern adhesive dentistry, a number of different materials and clinical procedures have been advocated to minimize some of most trouble some problems with direct posterior composites, and among several protocols, the use of flowable resin composite has been suggested as a means to reduce the possibility of microleakage ${ }^{(5,}$ 6).

The flowable resin materials have low viscosity, high flowability and are richer in resin than traditional composites, their elastic modulus is low, (it is about $50 \%$ of the conventional resins composite) so their tenacity values are better than those of conventional one ${ }^{(7)}$. It acts as buffer against the contraction forces of the overlaying composite resin during the curing process, so the flowable composites have been indicated as liners ${ }^{(8)}$.

The use of resin liner with flow, has been suggested as a mean to reduced the possibility of microleakage ${ }^{(9)}$.

Co-curing the adhesive and flowable composite has also been occasionally recommended, alhough supporting evidence is sparse ${ }^{(10,11,12)}$.

The objective of this invitro study was to investigate the microleakage in $\mathrm{Cl} \mathrm{V}$ composite restoration using flowable resin composite associated with an adhesive, either light cured separately or co-cured.

\section{MATERIALS AND METHODS}

Sixty, caries-free, restoration-free extracted human premolars were selected and stored in distilled water prior to the study, teeth thoroughly cleaned, then polished with a slurry of non fluoridated pumice and water in a rubber prophylaxis cup at a low speed, in order to obtain a clean, smooth and hard surface. The teeth were examined by fiber optic light to exclude crakes.

In each tooth a standardized box shaped class V cavity of $3.0 \mathrm{~mm}$ (mesialdistal), $2.0 \mathrm{~mm}$ (occlusal-gingival) and $2.0 \mathrm{~mm}$ depth was prepared using a cylindrical diamond bur No.556 in a high speed hand piece with air/water coolant on buc- cal surface, just below the cementoenamel junction, with enamel and dentin margins.

Each bur was used for Four preparation and then replaced. Cavities were received $0.5 \mathrm{~mm}$ bevel at a 45 angle on their occlusal margins, cervical margins ended at a 90 angle with the longitudinal surfaces of the teeth.

Preparation of the teeth, restoration and finishing were performed by one operator.

In all groups the total etch technique was performed prior the establishment of the adhesive layer. A 35\% phosphoric acid (Scothbond Etchant Gel, 3M - ESPE, st. paul, MN, USA) was applied initially to the enamel margins and then extended from the superficial to deep dentin for 20 sec. washing and drying, leaving moist dentin (avoid dentinal dehydration). The teeth were randomly assigned into three groups of twenty cavities each, according to the restorative technique used:

Group 1- Single bond Excite adhesive system (Ivoclar. Vivadent AG, 9494 Schaan/Liechtenstein) was applied according to the manufacturer's instructions and light cured with visible light source (Viva dent, Schaan Liechtenstein, Austria) for 20 second with a standard light at 480 $\mathrm{mw} / \mathrm{cm}^{2}$ assessed with a radiometer every 5 restorations. Then a hybrid composite resin (tetric ceram) (Ivoclar Vivadent AG, lot H29498 Schaan/Liechtenst) was placed and light cured for 40 second (control group).

Group 2- Single bond was applied in one layer that was gently air dried and covered with flowable resin composite (Tetric flow) (Ivoclar Vivadent CE, Lot $\mathrm{H}$ 31291 Schaan/ Liechenstein), which was inserted with a needle provided by the manufacturer. This two-component layer was co-cured (light cured simultaneously) for $40 \mathrm{sec}$, then tetric ceram hybrid composite was applied and light cured for 40 sec to restore the cavity.

In group 3- Bond was applied and light cured for $20 \mathrm{sec}$, flowable composite was placed with its special needles in the cavity and cured for $40 \mathrm{sec}$. Finally, a hybrid composite was placed and cured for 40 $\mathrm{sec}$, to complete the restoration.

The specimens maintained in distilled water for 1 week at $37{ }^{\circ} \mathrm{C}$ 
$\left( \pm 1{ }^{\circ} \mathrm{C}\right)$ after this period, the restorations were finished and polished with soft-lex sequential disks (3m Brasil Ltd., sumar, sp, Brazil).

All of the specimens were thermocycled for 300 cycles at temperature ranging from $5{ }^{\circ} \mathrm{C} \pm 2{ }^{\circ} \mathrm{C}$ to $55^{\circ} \mathrm{C} \pm 2{ }^{\circ} \mathrm{C}$, each cycle lasted $45 \mathrm{sec}$ with a dwell time of 15 $\mathrm{sec}$, in each path, and $15 \mathrm{sec}$. intervals between paths. The root apieces of the teeth were sealed with an a crylic resin and the entire tooth surfaces were painted with two coats of nail varnish except the restorations and one millimeter beyond the margins. The teeth were then immersed in buffered 2\% methylene blue solution at 37 ${ }^{\circ} \mathrm{C}$ for 24 hours, thoroughly rinsed with running water and stored in humidor. For evaluation, each tooth was longitudinally sectioned with a slow speed diamond sectioning disks in a buccal lingual direction through the middle of the restoration, the sections were evaluated by two independent calibrated examiners on the stereomicroscope (Hamilton by AItaly international Italy) at a magnification level of x 40 to determine the extend of dye penetration on the gingival and occulsal walls of the nest orations.

The following criteria were used to score the extend of the leakage at both enamel and dentin margins.

0 - No dye penetration

1- Dye penetration up to half of the cavity depth.

2- Dye penetration more than half of the cavity depth.

3- Dye penetration arriving to the cavity floor. (Fig 1)

Data were subjected to the Fisher Freeman Halton statistical test at a confidence level of $95 \%(\mathrm{p}<0.05)$.

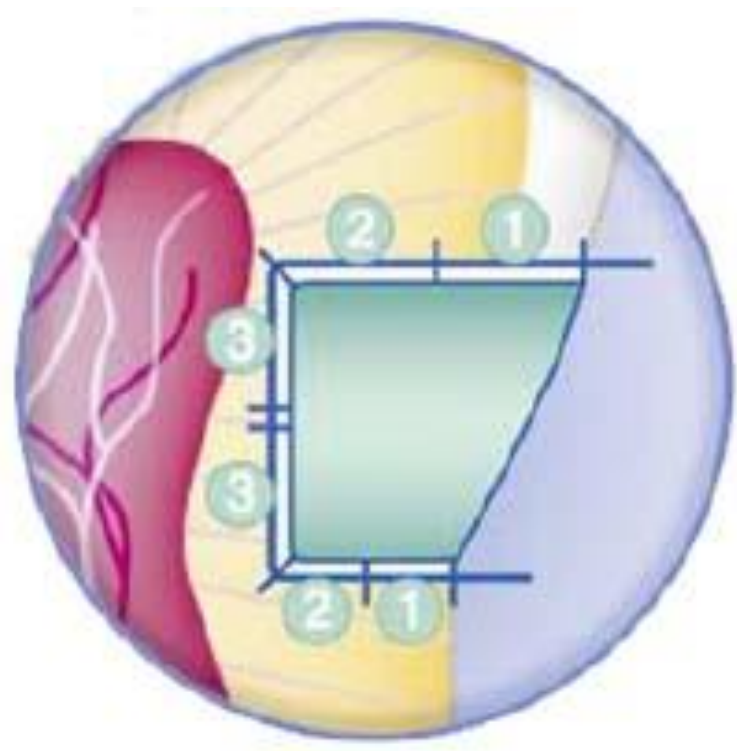

$0=$ No dye, $1=$ Dye penetration up to half of the cavity depth,

$2=$ Dye penetration more than half of the cavity depth,

$3=$ Dye penetration arriving the cavity floor.

Fig. (1) Diagram illustrated the score of dye penetration.

\section{RESULTS}

The frequency of microleakage score at enamel and dentin surfaces of the tested groups are reported in Tables (1) and (2). 
Table (1) The frequency of microleakage scores at enamel margins.

\begin{tabular}{|c|c|c|c|c|c|c|c|c|c|c|}
\hline \multirow{3}{*}{ Groups } & \multicolumn{8}{|c|}{ Site of leakage } & \multirow{2}{*}{\multicolumn{2}{|c|}{ Total }} \\
\hline & \multicolumn{2}{|c|}{$\mathbf{0}$} & \multicolumn{2}{|c|}{1} & \multicolumn{2}{|c|}{2} & \multicolumn{2}{|c|}{3} & & \\
\hline & No. & $\%$ & No. & $\%$ & No. & $\%$ & No. & $\%$ & No. & $\%$ \\
\hline G1 & 4 & 20.0 & 10 & 50.0 & 6 & 30.0 & 0 & 0.0 & 20 & 100 \\
\hline G2 & 8 & 40 & 10 & 50 & 2 & 10 & 0 & 0.0 & 20 & 100 \\
\hline G3 & 14 & 70.0 & 6 & 30.0 & 0 & 0.0 & 0 & 0.0 & 20 & 100 \\
\hline
\end{tabular}

Groups 2 and 3 has significant difference from group 1 at $p<0.05$ and $p<0.001$ respectively and group 3 has significant difference from group 2 at $p<0.05$.

Table (2) The frequency of microleakage scores at enamel margins.

\begin{tabular}{|c|c|c|c|c|c|c|c|c|c|c|}
\hline \multirow{3}{*}{ Groups } & \multicolumn{8}{|c|}{ Site of leakage } & \multirow{2}{*}{\multicolumn{2}{|c|}{ Total }} \\
\hline & \multicolumn{2}{|c|}{ 0 } & \multicolumn{2}{|c|}{1} & \multicolumn{2}{|c|}{2} & \multicolumn{2}{|c|}{3} & & \\
\hline & No. & $\%$ & No. & $\%$ & No. & $\%$ & No. & $\%$ & No. & $\%$ \\
\hline G1 & 0 & 0.0 & 0 & 0.0 & 12 & 60.0 & 8 & 40.0 & 20 & 100 \\
\hline G2 & 0 & 0.0 & 4 & 20.0 & 10 & 50.0 & 6 & 30.0 & 20 & 100 \\
\hline G3 & 0 & 0.0 & 8 & 40.0 & 8 & 40.0 & 4 & 20.0 & 20 & 100 \\
\hline
\end{tabular}

Groups 2 and 3 has significant difference from group 1 at $p<0.05$ and $p<0.001$ respectively and group 3 has significant difference from group 2 at $\mathrm{p}<0.05$.

Non parametric Fisher Freeman Halton test revealed a significant differences in microleakage score between the tested groups for both enamel and dentin margins.
In most of the sections, the cervical margins presented higher leakage score than occlusal margins (Fig. 1).

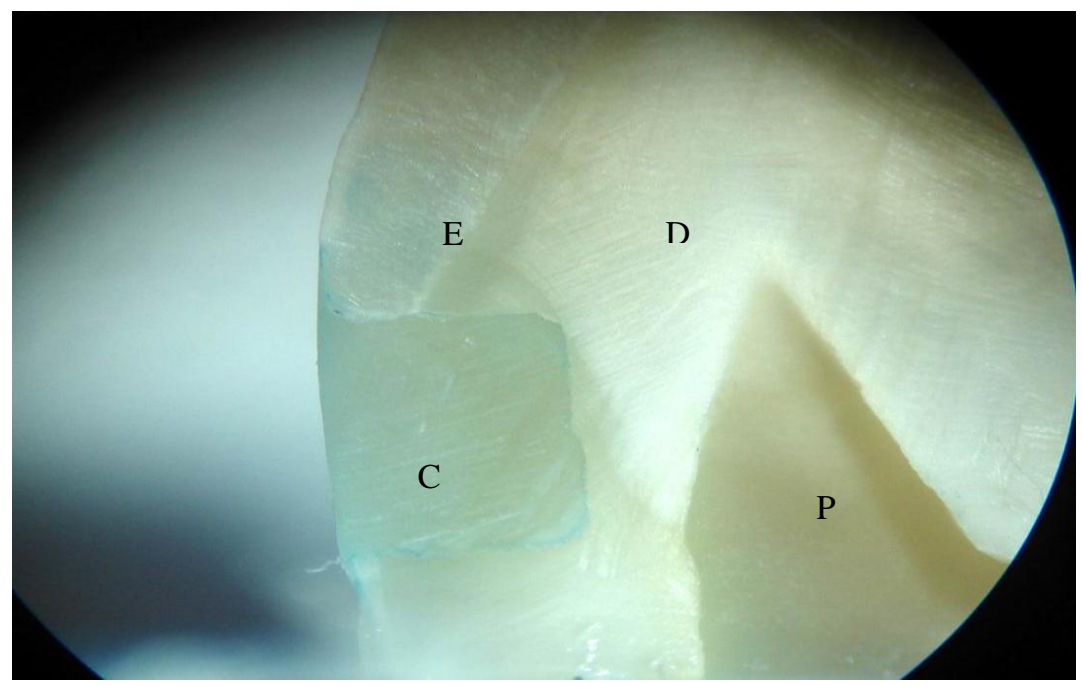

$\mathrm{E}=$ Enamel, $\mathrm{D}=$ Dentin, $\mathrm{C}=$ Composite and $\mathrm{P}=\mathrm{Pulp}$

Fig. (2) Sectional tooth see the degree of dye penetration.

Differences in microleakage patterns and scores were observed between Group 1 (control group) and Group 3 at ( $\mathrm{p}<$ $0.001)$ and Group 2 with Group 3 at $(\mathrm{p}<$ 0.05 ) for both enamel and dentin margins.
That is mean in the present study the marginal adaptation of the resin composite restorative system was improved by the use of flowable resin composite as liner. 
Group 3 (adhesive and flowable composite cured separately) yield the best results, and provided better marginal seals.

\section{DISCUSSION}

Composite resin still presented with relevant draw backs such as inherent polymerization shrinkage, which result contraction gaps at the tooth/restoration interface that lead to microleakage ${ }^{(13)}$. When composite resin are the material of choice for cervical defects or class V cavities this represents a challenge and technically demanding situation because the gingival margins usually located in the dentin or cementum, which is considered a critical factor governing the marginal adaptation $^{(14)}$.

In the present study, higher leakage was detected in dentin when compared to enamel. These differences might be related to the compositions of these tissues, while the enamel is almost completely mineralized, dentin present with a lower mineral content, with an organic matrix having a moist surface which impairs the bonding mechanism $(15,16)$

Therefore the bond strength to enamel is typically stronger and more stable than that obtained with dentin, and leakage along the enamel/restoration interface is less than that of dentin ${ }^{(17,18)}$.

The restorative technique with resin elastic liners and rigid restorative composites might be suitable alternative to reduce stress at the dentin/composite interface, flowable resin composite can used as an intermediate layer and this methods proposed to increase the longevity of composite restorations, especially those with margins in dentin ${ }^{(19)}$

The main rationale behind the use of flowable resin composite is the formation of an elastic layer that may compensate for polymerization shrinkage stress. Montes et $\mathrm{al}^{(20)}$ suggested that the use of an intermediate low elastic modulus layer would function as an shock absorber or a "stressbreaker"

The results of the present study showed that the use of flowable resin composite (with adhesive cured separately under hybrid composite Group 3) exhibited less microscopical leakage than con- trol group. This finding are in agreement with the finding of other studies. ${ }^{6,8,9,21}$ and 22)

The low viscosity of tetric flow wilh its handling characteristic, allow the material to readily adapt to the prepared tooth structure creating an intimate union with the microstructural defects of the of the prepared cavities.

Li Q et al ${ }^{(8)}$ studied the influences of flowable materials as an intermediate layer in class $\mathrm{V}$ cavities, his results showed that composite fillings could be improved by the use of flowable composite materials.

Group 2, (the adhesive system cocured with the flowable composite simultaneously) has been advocated as a mean to improve the marginal sealing of adhesive restorations. ${ }^{(11)}$

As the oxygen inhibition layer could prevent the adequate polymerization of the adhesive, a flowable composite may ensure this oxygen inhibition layer is blocked out prior to polymerization of the dentin bonding agent ${ }^{(3)}$.

In this study the use of a flowable composite light cured simultaneously with the adhesive did not improved the marginal sealing like the teeth in group 3 (when the flowable resin and adhesive cured separately). This result in agreement with Sensi et al. ${ }^{(3)}$ who concluded that adhesive system should not be co-cured with flowable composite.

This might be related to the displacement of the bonding agent leaving unprotected zone that may cause adhesive failure and subsequent increase in the microleakage score.

Despite the methodological and criterial differences, the results achieved with this study is in accordance with similar studies ${ }^{(3,9)}$.

From clinical point of view, the tooth/composite restoration interface in class V cavities could improved by the use of flowable resin materials with rigid composite resin such as hybrid resin.

Although, in this study an effort was made to simulate the clinical situation, but, ideally, long term clinical studies should by performed to evaluate the performance of the flowable resin composite when used with hybrid composite. 


\section{Conclusion}

- The dentin margins demonstrated more leakage as compared to enamel margins.

- Non of the restorative techniques or materials completely sealed the tooth/restoration interface especially in the cervical margins.

- The use of flowable resin material may be advantageous in reducing the microleakage level.

- It is not preferable to co-cured the flowable composite with the adhesive system.

\section{REFERENCES}

1. Burgress Jo Dental materials for the restoration of root surface caries. Am J Dent 1995; 8: 342-351.

2. Carvalho RM, pereira JC, Yoshiyama M and Pashley DH. A review of polymerization contraction: The influence of stress development versus stress relief. Oper Dent 1996; 21(1) 17-24.

3. Sensi LG, Monteiro Jr S, Baratieri LN, and Andrada MA. Flowable composite as "filled adhesive" A microleakage study. J Contem Dent pract. 2004; (5)4: 32-41.

4. Kimuro Y, Yonago K, Yokoyama, Matsuoka, saki $\mathrm{K}$ and Matsumoto K Apical leakage of obturated canals prepared by Er. YAG laser. Am Assoc Endod 2001; 27: 567-569.

5. Montes MA JR, De Goes MF, Ambrosano GM. The effect of collagen removal and the use of low viscosity resin liner on marginal adaptation of resin composite restorations with margins in dentin. Oper Dent. 2003; 28: 378-387.

6. Peutzfeldt A, Asmussen E, composite restorations influence of flowable and self curing resin composite linings on microleakage invitro. Oper Dent 2002; 27(6): 569-575.

7. Bayne Sc., Thompson Jy, swift Jr EJ, Stamatiades P, Wilkerson M. A characterization of first generation flowable composites. J Am Dent Assoc 1998; 129: 567577.

8. Li Q, Jepsen S, Albers HK, Eberhard J. Flowable materials a an intermediate layer could improve the marginal and internal adaptation of composite restorations in class V cavities. Dent Mater 2006; 22(3) 250-257.

9. Yazici AR. Baseren M, Dayangac B. The effect of flowable composite resin on microleakage in class V oper Dent 2003; 28: 42-46.

10. Maxson BB, Kashani N, Neme Al Microleakage of composite restorations with cocured bonding agent. J. Dent Res 2002; 81 Abstract: 418.

11.Unterbrink GL, Liebenberg WH. Flowable resin composites as "filled adhesives": literature review and clinical recommendations Quintessence Int. 1999; 30(4): 249257.

12.Piva E, Meinhardt L, Demarco FF, powers JM. Dyes for caries detection: influence on composite and compomer microleakage. Clin Oral Investig. 2002; 6: 244-248.

13.Kemp-Scholte CM, Davidson GL. Marginal sealing of curing contraction gaps in class V composite resin restorations. J Dent Res 1988; 67: 841-845.

14.Baratieri LN, Canabarro S, Lopes GC. Effect of resin viscosity and enamel beveling on the clinical performance of class $\mathrm{V}$ composite restorations three year results. Oper Dent 2003; 28: 482-487.

15.De Munck J, Van Landuyt K, Peumans M, poitevin A, Lambrechts P, Braem M, Van Meerbeek B. A critical review of the durability of adhesion to tooth tissue methods and results. J Dent Res. 2005; 84 : 118-132.

16.Eick JD, Gwinnett AJ, Pashley DH, Robinson SJ. Current concepts on adhesion to dentin. Crit Rev Oral Biol Med 1997; 8: 306-335.

17.Santini A, Ivanovic V, Ibbetson R, Milia. Influence of cavity con figuration on microleakage around class $\mathrm{V}$ restorations bonded with seven self etching adhesives. J. Esthet Restor Dent. 2004; 16: 128-135.

18. Araujo C, ogllari F, Piva, E. Microleakage of seven Adhesive system in Enamel and Dentin. J Contem Dent Pract. 2006; 7(5): 26-33.

19.Bedran-Russo A, Swift JR E, class II composite resin restorations with gingival margins in dentin J Esthet Resto Dent. 2007; 19(3): 171-177.

20.Montes MAJR, De Goes MF, Cunha MRB, Soares AB. A morphological and tensile bond strength evaluation of an unfilled adhesive with low-viscosity composites and a filled adhesive in one and two coats J Dent 2001; 29: 435-441.

21.Alonso RC, Sinhoreti MA, Sobrinho LC, 
Consani S, De Goes MF Effect of resin liners on the microleakage of class $\mathrm{V}$ dental composite restorations J. Appl oral sci 2004; 12(1): 56-61.

22. Cho E, Chikawa H, Kishikawa R, Inai N,
Otsuki M, Foxton RM, Taqami J. Influence of elasticity on gap formation in a lining technique with flowable composite. Dent Mater 2006;25(3):538-544. 